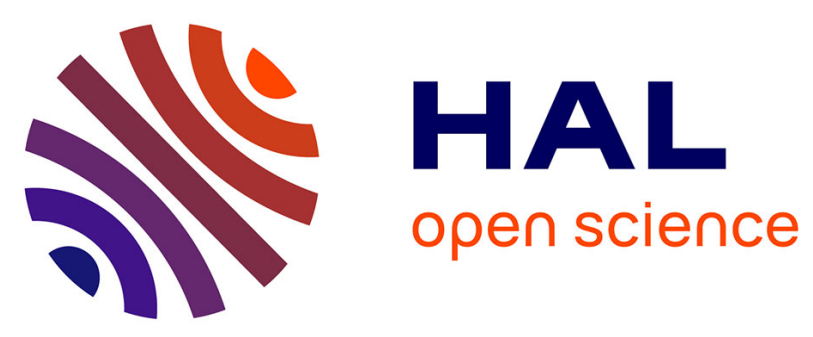

\title{
Development of Coprocessed Chitin-Calcium Carbonate as Multifunctional Tablet Excipient for Direct Compression, Part 2: Tableting Properties
}

Mohammad Chaheen, Bernard Bataille, Ahmad Yassine, Emmanuel Belamie, Tahmer Sharkawi

\section{- To cite this version:}

Mohammad Chaheen, Bernard Bataille, Ahmad Yassine, Emmanuel Belamie, Tahmer Sharkawi. Development of Coprocessed Chitin-Calcium Carbonate as Multifunctional Tablet Excipient for Direct Compression, Part 2: Tableting Properties. Journal of Pharmaceutical Sciences, 2019, 108 (10), pp.3319-3328. 10.1016/j.xphs.2019.05.021 . hal-02381549

\section{HAL Id: hal-02381549 \\ https://hal.umontpellier.fr/hal-02381549}

Submitted on 21 Dec 2021

HAL is a multi-disciplinary open access archive for the deposit and dissemination of scientific research documents, whether they are published or not. The documents may come from teaching and research institutions in France or abroad, or from public or private research centers.
L'archive ouverte pluridisciplinaire HAL, est destinée au dépôt et à la diffusion de documents scientifiques de niveau recherche, publiés ou non, émanant des établissements d'enseignement et de recherche français ou étrangers, des laboratoires publics ou privés.

\section{(ㄷ)(1) $\$$}

Distributed under a Creative Commons Attribution - NonCommerciall 4.0 International 


\title{
Development of Coprocessed Chitin-Calcium Carbonate as Multifunctional Tablet Excipient for Direct Compression, Part 2: Tableting Properties
}

\author{
Mohammad CHAHEEN 1,2,*, Bernard BATAILLE ${ }^{2}$, Ahmad YASSINE ${ }^{1}$, \\ Emmanuel BELAMIE ${ }^{3}$, Tahmer SHARKAWI ${ }^{2 *}$ \\ 1: Ecole Doctorale des Sciences et Technologie (EDST), Laboratoire de Valorisation des Ressources \\ Naturelles et Produits de Santé (VRNPS), Université Libanaise, Beyrouth, Liban. \\ 2: Institut Charles Gerhardt, UMR 5253, Equipe MACS, UFR Sciences Pharmaceutiques et Biologiques, \\ Université de Montpellier, France. \\ 3: Institut Charles Gerhardt, UMR 5253, EPHE, PSL ; Equipe MACS, Ecole Nationale Supérieure de Chimie, \\ Université de Montpellier, Montpellier, France.
}

\begin{abstract}
The use of multifunctional excipients is gaining interest as it simplifies formulations by replacing the need of multiple monofunctional excipients. In previous work, coprocessed ChitinCalcium carbonate (CC) showed to have good potential as a multifunctional excipient for fast disintegrating tablets produced by direct compression. It allowed for good tablet strength, enhanced powder flowability, higher true and bulk densities with fast disintegrating properties. The objective of this work is to gain insight on CC tableting properties under different tablet manufacturing conditions (different lubrication levels, compression speeds and dwell times) and in formulations with drug models: ibuprofen and paracetamol. Results showed that CC exhibited good tabletability, compressibility and compactibility profiles. CC does not require the addition of lubricant and can be used at high compression speeds and different dwell times. When included in formulations with ibuprofen and paracetamol at different percentages, $\mathrm{CC}$ enhanced tablets strength and promoted fast disintegration and drug dissolution. In conclusion, this study shows that $\mathrm{CC}$ can be used as a multifunctional excipient (filler-disintegrant-binder) for fast disintegrating tablets produced by direct compression.
\end{abstract}

Keywords: Multifunctional excipient; Chitin-calcium carbonate; Rapid disintegration, Compaction; Dissolution.

\footnotetext{
${ }^{*}$ Corresponding author: E-mail address: mohammadchaheen@hotmail.com, Telephone: +96170160944, Fax: +33411759552, tahmer.sharkawi@umontpellier.fr
} 


\section{Introduction}

Pharmaceutical tablets administered by the oral route remains the most preferred method of drug delivery due to convenience, patient adherence, and reasonable production costs of this pharmaceutical dosage form. A typical tablet formulation consists of the active pharmaceutical ingredient (API) and excipients used for different functionalities. For example, fillers are used to increase the bulk of the tablet, disintegrants to promote tablet disintegration, and lubricants to lubricate the punch-die interface during tablet manufacturing. There are 3 main methods used for tablet manufacturing: wet granulation, dry granulation and direct compression. Among the mentioned methods, direct compression is considered as the simplest one as it involves fewer steps and no heat or solvents are needed. However, not all formulations can be used in direct compression. The powders composing the formulation need to meet specific requirements such as good flowability, similar characteristics (density particle size, etc.) in order to be processed by direct compression [1-4].

The use of multiple individual excipients in a tablet formulation for direct compression thus raises the potential for problematic processing by direct compression. Firstly, physicochemical incompatibility could occur between excipients themselves or the excipients and the API. Secondly, the more excipients used, the more the chance of having some heterogeneities in certain physical characteristics (particle size, surface, density,...) leading to potential powder flowability or demixing problems. Finally, the use of multiple individual excipients could be expensive [1,5]. In order to overcome these problems, researchers in pharmaceutical technology have developed multifunctional excipients that replace the need of multiple individual excipients. With multifunctional excipients, formulations are more robust and simplified and manufacturing efficiency is improved. In addition, the use of multifunctional excipients lowers production cost and time and minimizes scale-up variability. Finally, multifunctional excipients have easier regulatory criteria process for approval $[6,7]$.

One of the most important methods used for the production of multifunctional excipients is excipients coprocessing. Pharmaceutical excipients coprocessing is a combination of two or more established excipients by a pharmaceutical process without the formation of covalent bonds. Different methods are used for coprocessing such as spray drying, coprecipitation, 
comilling, hot melt extrusion and others. The coprocessed products are physically modified such that they do not lose their chemical structure and stability. In addition, products must demonstrate one or more different properties from a physical mixture of initial excipients. Among the advantages of excipients coprocessing is the ability to improve powder flowability, compressibility and reduce lubricant sensitivity [8-10].

In our previous work, we reported the potential use of a coprocessed chitin-calcium carbonate (CC) as a new multifunctional excipients for direct compression. Chitin showed excellent cohesiveness as a filler as well as excellent disintegration properties. It did however lack flowability to be used in an industrial compression process. We therefore undertook a modification through coprocessing with calcium carbonate. The excipient was produced through precipitation of calcium carbonate $\left(\mathrm{CaCO}_{3}\right)$ on chitin's surface and characterized for different physicochemical and functional properties where it showed acceptable tensile strength, enhanced powder flowability, higher true and bulk densities, and fast disintegration properties [11]. In order to further contribute to the understanding of this new coprocessed excipient we studied the powder compression behavior in simulated industrial compression conditions. The objective of this work is to study CC tableting properties. Firstly, a compaction profile (tabletability, compressibility and compactibility) of $\mathrm{CC}$ and study in different manufacturing conditions (lubrication level, compression speed and dwell time) was made. Secondly this compaction profile was evaluated in formulations with 2 different APIs: ibuprofen and paracetamol at different concentrations to study effect on tablet properties, deformation and determine the minimal effective percentage of the excipient to be included.

\section{Materials and methods}

\section{II.1 Materials}

Chitin 60 mesh (Mahtani Chitosan, India), sodium carbonate $\left(\mathrm{Na}_{2} \mathrm{CO}_{3}\right)$ (Cooper, France), anhydrous calcium chloride $\left(\mathrm{CaCl}_{2}\right)$ (Panreac, Germany), Ludiflash ${ }^{\circledR}$ (BASF, France), Prosolv SMCC $^{\circledR} 90$ (JRS Pharma, France), ibuprofen (Fagron, France) and paracetamol (Fagron, France) were used as reagents. 
CC was prepared as reported in our previous work [11]. Briefly, chitin is suspended in $\mathrm{Na}_{2} \mathrm{CO}_{3}$ solution, and $\mathrm{CaCl}_{2}$ solution was then added dropwise to precipitate $\mathrm{CaCO}_{3}$. The solution was then filtered and powder washed with water over a $50 \mu \mathrm{m}$ mesh (chosen according to particle size analysis to remove free $\mathrm{CaCO}_{3}$ aggregates). Finally the powder was dried and stored for further characterization.

Ludiflash $^{\circledR}$ is a commercial multifunctional excipient used as filler, binder and disintegrant. It is composed of $90 \%$ mannitol, $5 \%$ Kollidon CL-SF ${ }^{\circledR}$ (Crospovidone), $5 \%$ Kollicoat SR 30D ${ }^{\circledR}$ (polyvinyl acetate). It is used in the production of orodispersible tablets [12]. Ludiflash ${ }^{\circledR}$ was chosen as a reference against CC as it is a coprocessed excipient exhibiting similar functionality.

Prosolv SMCC ${ }^{\circledR}$ (silicified microcrystalline cellulose) is a commercial multifunctional excipient composed of microcrystalline cellulose and colloidal silicon dioxide. It is used as a control against $\mathrm{CC}$ as it exhibits both brittle fracture and plastic deformation characteristics, and considered as lubricant insensitive material [13] .

\section{II.2 Methods}

\section{II.2.a Textural-morphological observations}

Particle morphology was evaluated by scanning electron microscopy using a Hitachi 4800-S electronic microscope (Hitachi, Japan) at different magnifications.

Chitin and CC powder samples were examined by transmission electron microscopy (Jeol 200CX - Massachusetts, USA) with a resolution of $3,5 \AA$ after sectioning of resin embedded particles to follow the presence of $\mathrm{CaCO}_{3}$ and their distribution.

\section{II.2.b Compaction profile}

The tabletability, compressibility and compactibility of the studied powder and compacts were analyzed at different compaction pressures (100-400 MPa). In addition, lubrication study was carried out by mixing the powder with different concentrations of Magnesium Stearate (MgSt) $(0.5,1,2$ and $5 \%)$ to study the effect of lubrication on tablet tensile strength, powder deformation, disintegration time and ejection properties. The lubricated mixtures were prepared 
using Turbula ${ }^{\circledR}$ mixer (WAB, Switzerland) by powder mixing for $10 \mathrm{~min}$ at $49 \mathrm{rpm}$ to ensure homogeneous and uniform mixture.

Speed study was realized by compressing tablets at different machine speeds $10,25,50$ and $100 \%$ (1750 tablet per hour - $400 \mathrm{~mm} / \mathrm{s}$ linear punch speed). In addition, dwell time effect was examined by tablet production at different dwell times (1, 2 and $3 \mathrm{~s})$. The effect of production speed and dwell time on tablets tensile strength, powder deformation and disintegration time was investigated.

For each of the above mentioned studies, $400 \mathrm{mg}$ tablets were produced at $100-400 \mathrm{MPa}$ using Styl'One ${ }^{\circledR}$ rotary press simulator. Tablets tensile strength was calculated using hardness, thickness and diameter data measured by Pharmatron Multitest50 ${ }^{\circledR}$ (Solothurn, Switzerland). Powder deformation behavior was assessed using Heckel model analysis and $\mathrm{P}_{\mathrm{y}}$ was used to compare different powder deformation behaviors (using Analis ${ }^{\circledR}$ software). Tablet solid fraction was determined automatically using the compression simulator. In the compression studies, 3 reference powders were used as controls: chitin, Ludiflash ${ }^{\circledR}$ and dry mix of chitin and $\mathrm{CaCO}_{3}$ at the same ratio used for the coprocessed excipient.

Disintegration time test of $400 \mathrm{mg}$ pure tablets was performed according to the European pharmacopeia guidelines [14]. The used apparatus consists of basket-rack assembly described in the pharmacopeia monograph for normal size tablet disintegration (Erweka ZT-31, Germany). Six tablets of each powder were evaluated simultaneously and the results expressed as the mean value with standard deviation. The end point was achieved when no residues were present on the screen of the test basket.

Formulation tablets containing API were first prepared by mixing CC-API at different percentages $\left(50-50,40-60,30-70,25-75\right.$ and 20-80 \%) using Turbula ${ }^{\circledR}$ mixer for $10 \mathrm{~min}$, and then compressing using the Styl'One ${ }^{\circledR}$ tablet compression simulator. Dissolution test was carried out using dissolution tester (Pharmatest DT70, Germany) as described in the European pharmacopeia [15]. Phosphate buffers of $\mathrm{pH} 6.8$ and 5.8 were used as dissolution media for ibuprofen and paracetamol respectively [16]. The dissolution study was conducted using $900 \mathrm{ml}$ of the media at $37^{\circ}$ using the paddle apparatus and stirring rate of $50 \mathrm{rpm}$. Samples were withdrawn automatically each 30 s and analyzed using a continuous flow-through system 
attached to an 8 cell UV/Vis spectrophotometer (Specord 250, Germany) at a wavelength of 264 $\mathrm{nm}$. For each formulation, the experiment was carried out for 6 tablets and results were expressed as mean values with standard deviation.

\section{Results and Discussion}

\section{III.1 Textural-morphological observations}

CC scanning electron microscopy showed regular and homogeneous distribution of rhombohedral $\mathrm{CaCO}_{3}$ particles on chitin' surface with no multilayer coverage (figure 1). The particle size analysis showed no large difference between the mean weighted volume of chitin $(220 \mu \mathrm{m})$ and $\mathrm{CC}(210 \mu \mathrm{m})$

With respect to transmission electron microscopy analysis and as observed in figure 2 , Images A and B (increasing magnification) for chitin (left) and CC (right) reveal the fibrous structure due to the presence of elongated crystalline fibers of $\alpha$-chitin. At higher magnification (B) the contrast is poor with chitin only, while it is enhanced in the presence of $\mathrm{CaCO}_{3}$ which appears to highlight the chitinous elongated structures. At even higher magnification (C), dark dots suggest the presence of $\mathrm{CaCO}_{3}$ particles possibly aligned along the chitin nanocrystals. The inset in $\mathrm{C}$ is approx. $50 \mathrm{~nm}$ wide. The histogram shows the dark dots size distribution as determined with Image ${ }^{\circledR}$ from images as in C.

\section{III.2 Tabletability-compressibility-compactibility}

Figure 3 depicts the tabletability, compressibility and compactibility profiles of the studied powders. As illustrated in the figure, Prosolv ${ }^{\circledR}$ tablets have the highest tensile strength at all compaction pressures followed by chitin. This is mainly due to the plastic deformation and high bond formation ability. Despite acceptable CC tablets strength (hardness $>40 \mathrm{~N}$ ) at compaction pressure $\geq 140 \mathrm{MPa}$, CC tablets showed the lowest strength among the studied powders. Ludiflash ${ }^{\circledR}$ tablets underwent sticking at pressure $\geq 200 \mathrm{MPa}$ as mannitol is routinely used with MgSt during compaction to avoid sticking especially at high compression forces [17]. As the compaction pressure increases, the solid fraction increases as a result of a decrease in tablet porosity. In addition to Prosolv ${ }^{\circledR}$, dry mix and chitin tablets give stronger compacts than other powder at a given solid fraction due to higher chitin-chitin particle interaction. At solid 
fractions $>0.9, \mathrm{CC}$ tablets had higher tensile strength than Ludiflash ${ }^{\circledR}$ tablets. At the powder level and compared to chitin, $\mathrm{CC}$ powder showed improvement in die filling due to the enhancement in powder flowability and less segregation [11].

\section{III.3 Lubrication}

\section{III.3.a Tensile strength and tablet ejection}

Figure 4 shows at $200 \mathrm{MPa}$ the tablets tensile strength as a function of $\mathrm{MgSt} \%$ in the mixture. The behavior was similar at 100, 300 and $400 \mathrm{MPa}$. For all powders except for CC$0.5 \% \mathrm{MgSt}$, we can observe a decrease in tablets tensile strength with the increase in $\mathrm{MgSt} \%$. This represents a typical behavior of lubricant and material with more plastic deformation.

As for $\mathrm{CC}, \mathrm{MgSt}$ at $0.5 \%$ leads to a light increase in tablets tensile strength, this is explained by the higher solid fraction possibly to due to better particle arrangement. As $\mathrm{MgSt} \%$ increased, the tensile strength decreased but remained acceptable at all compaction pressures, except for $\mathrm{CC}$ at $0.5 \% \mathrm{MgSt}$ where higher tensile strength observed due to higher solid fraction (supplementary data). Compared to chitin, CC tablets have lower sensitivity to lubrication $\mathrm{MgSt} \%$ and compaction pressures. This is coherent with literature that reports that the increase in the concentration of $\mathrm{MgSt}$ lead to a decrease in tablet hardness due to interparticular lubrication which prevents cohesion and an increase in disintegration time due to the increased hydrophobicity [18]. Lubricants have more influence on tablet hardness for plastic deforming materials such as microcrystalline cellulose, lactose and starch because for such materials no new surface is created during the deformation contrary to brittle material like mannitol, $\mathrm{CaCO}_{3}$ or phosphate [19]. For CC tablets, no tablet defects (capping, sticking) were observed at all lubricant concentrations and compaction pressures.

For chitin and dry mix tablets, when the percentage of MgSt increased to 5\%, tablets capping was observed at all compaction pressures due to the lack of cohesion brought upon the excessive lubrication [20].The dry mix showed higher tensile strength compared to CC tablets. This could be explained by that in the case of $\mathrm{CC}, \mathrm{CaCO}_{3}$ particles are more homogeneously distributed over chitin's surface that lead to higher interference of the chitin-chitin particle interactions than in case of the dry mix. Also, the infrared analysis showed less interaction 
between the $\mathrm{CaCO}_{3}$ and the chitin particles in the dry mix compared to the coprocessed powder [11].

Ludiflash $^{\circledR}$ tablets are less sensitive to lubrication as they are composed of $90 \%$ mannitol which is a fragmentary material and subsequently less affected by lubrication [17]. Ludiflash ${ }^{\circledR}$ tablets developed an acceptable tensile strength with different $\mathrm{MgSt} \%$ at all compaction pressures.

Figure 5 shows the ejection force of tablets compressed at $200 \mathrm{MPa}$ without lubricant. Pure chitin tablets have the lowest ejection force whereas Ludiflash ${ }^{\circledR}$ has the highest ejection force. Even at $0.5 \% \mathrm{MgSt}$, Ludiflash ${ }^{\circledR}$ kept sticking whereas chitin and $\mathrm{CC}$ tablets had acceptable ejection force. Although further studies including different press profiles and industrial conditions (Temperature, Humidity, Etc) would be more informative, these results suggest that the chitin containing tablets need less lubricant during formulation and can be related to the more plastic deformation behavior with less new surfaces being created then for a more fragmentary deformation material which creates more surfaces and hence more potential for adhesion to tooling.

\section{III.3.b Powder deformation}

The mean yield pressure $\left(\mathrm{P}_{\mathrm{y}}\right)$ obtained by Heckel modeling is used as a comparative indicator when comparing powder deformation behaviors. Figure 6a shows $\mathrm{P}_{\mathrm{y}}$ of the studied powder at $200 \mathrm{MPa}$ compaction pressure. As observed in the figure, the increase in $\mathrm{MgSt} \%$ did not lead to a significant change in $\mathrm{P}_{\mathrm{y}}$. This is also confirmed in figure $6 \mathrm{~b}$ from Heckel plots that showed no change in powder behavior and deformation obtained with different $\mathrm{MgSt} \%$.

$\mathrm{CC} \mathrm{P}_{\mathrm{y}}$ was found to be higher than that of chitin, which is expected as the introduction of $\mathrm{CaCO}_{3}$ (fragmentary material) in the formulation leads to a decrease in plastic deformation ability. No significant difference was observed in $\mathrm{P}_{\mathrm{y}}$ for $\mathrm{CC}$ and dry mix tablets. By comparing the $\mathrm{P}_{\mathrm{y}}$ of the different powders without $\mathrm{MgSt}$, it is possible to rank the powders plastic deformability as follows: chitin, Ludiflash ${ }^{\circledR}, \mathrm{CC} \approx$ Dry mix and Prosolv ${ }^{\circledR}$. Microcrystalline cellulose is known to have higher plastic deformability compared to chitin [21]. 


\section{III.3.c Tablet disintegration}

Figure 7 shows the disintegration time for tablets compressed at $200 \mathrm{MPa}$ with different $\mathrm{MgSt} \%$. CC tablets showed the fastest disintegration -time at all MgSt\% while prosolv tablets did not disintegrate (stayed intact even after $20 \mathrm{~min}$ ), this is explained by the strong adhesion due to the hydrogen bonds that makes water as a solvent insufficient for disintegration [22]. It is interesting to notice that at $5 \% \mathrm{MgSt}$, Ludiflash ${ }^{\circledR}$ disintegration time was really affected whereas, despite some increase in disintegration time, the chitin containing tablets were a lot less affected at this high MgSt concentration. When comparing CC and Chitin, Tensile strength is not the major contributor to the lower disintegration time obtained for the coprocessed CC tablets. Although the coprocessed tablets have lower tensile strength compared to other tablets, when we compare their disintegration time with that of other tablets with the same tensile strength, a faster disintegration was observed with coprocessed tablets revealing a clear benefit in terms of disintegration time for the coprocessed excipient. For example: CC- $0.5 \% \mathrm{MgSt}$ and Ludiflash ${ }^{\circledR_{-}}$ $2 \% \mathrm{MgSt}$ compressed at $200 \mathrm{MPa}$ have same tensile strength but the disintegration time was lower for CC (3s) than Ludiflash ${ }^{\circledR}$ tablets (26s). Another example is chitin-2\% MgSt compressed at $100 \mathrm{MPa}$ and pure $\mathrm{CC}$ tablets compressed at $200 \mathrm{MPa}$, the tablets have the same tensile strength, but the disintegration time for CC tablets (3s) is lower than that of chitin tablets (18s).

This behavior confirms what we previously reported as to the potential of $\mathrm{CC}$ as a robust multifunctional excipient for fast disintegrating formulations. The robust disintegration is most likely due to the shape recovery of the chitin which is less dependent on the overall hydrophobicity compared to the dissolution of the mannitol in the Ludiflash ${ }^{\circledR}$ for example.

\section{III.4 Compression velocity}

The effect of production speed and thus compression velocity on powder deformation and tablet properties was studied. $400 \mathrm{mg}$ tablets were produced at different ratios $(10,25,50$ and $100 \%)$ of the maximum compression speeds for the selected simulator profile $(400 \mathrm{~mm} / \mathrm{s})$ and analyzed for tensile strength, powder deformation and disintegration time.

\section{III.4.a Tensile strength}

Figure 8 shows the tensile strength of tablets produced with different compression velocities. The behavior was similar at different compaction pressures (100-400 MPa) With 
respect to $\mathrm{CC}$ and chitin tablets, at the same compaction pressure, the increase in compression velocity leads to a decrease in the tensile strength of the produced tablets. This is coherent with the results of Cook and Summers who found that higher compression velocities are associated with lower tablet strength due to the lower time available for plastic deformation and bond formation [23]. The dry mix and Ludiflash ${ }^{\circledR}$ tablets are less affected by this change at 100-200 MPa. Ludiflash ${ }^{\circledR}$ tablets showed sticking when compressed at 300-400 MPa. Prosolv ${ }^{\circledR}$ tablets showed low sensitivity to the variation in compression speed.

Chitin tablets had the highest tensile strength at all compression speeds and compaction pressures. No tablet defects (capping, sticking) were observed with CC tablets at all compression speeds and pressures.

\section{III.4.b Powder deformation}

Regarding powder deformation and as illustrated in figure 9, an increase in the compression velocity leads to a tendency of increase in $\mathrm{P}_{\mathrm{y}}$ except for Prosolv ${ }^{\circledR}$ (negligible

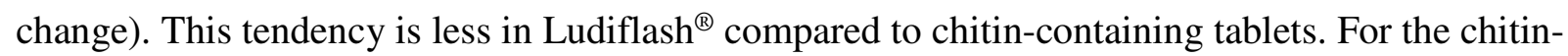
containing tablets, this reflects change either from ductile to brittle behavior or a reduction in the amount of plastic deformation due to the time dependent nature of plastic flow of viscoelastic materials as reported by Roberts and Row [24]. This effect is less pronounced for fragmentary deforming materials.

\section{III.4.c Tablet disintegration}

An increase in the compression speed is associated generally with a decrease in the disintegration time (except for chitin at $25 \%$ ) noticed mainly at higher speeds. This could be explained by the lower strength of the tablets compressed at higher speeds. The order of tablets disintegration time from faster to slower at the same speed is: CC, Ludiflash ${ }^{\circledR}$, dry mix and chitin. Prosolv ${ }^{\circledR}$ tablets did not disintegrate.

\section{III.5 Dwell time}

Dwell time is defined as the time at which the distance between the 2 punches is minimal. It is usually associated with the maximal force applied by the 2 punches on the powder bed 
during tablet compression. The effect of different dwell times $(0,1,2$ and $3 \mathrm{~s})$ on tablet tensile strength, powder deformation and disintegration time was investigated.

\section{III.5.a Tensile strength}

Figure 10 shows the tensile strength of tablets produced with different dwell times at different compaction pressures. In general, an increase in the dwell time leads to higher tablet

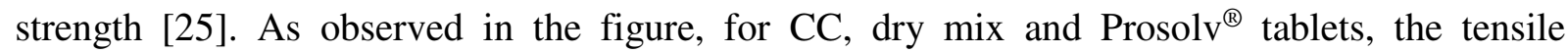
strength increased with increased dwell times between 0 and 1 second and was constant thereafter. For chitin, further increase in dwell time lead to an increase in tablet strength. This is due to the fact that the maximal solid fraction and thus the maximum particle-particle interaction is attained after 1s dwell time (supplementary data). Chitin tablets solid fraction kept increasing resulting in more inter-particulate bonding responsible for higher tensile strength of the tablets. At 300-400 MPa compaction pressures, Ludiflash ${ }^{\circledR}$ tablets underwent sticking. It has been reported previously that as dwell time becomes shorter, stress relaxation is reduced and less particle-particle bonds are formed where a decrease in the plastic to elastic energy ratio is observed contributing to lower tensile strength of tablets [26,27].

$\mathrm{CC}$ tablets showed acceptable tensile strength at all dwell times and different compaction pressures, except at $100 \mathrm{MPa}$ without any dwell. The tensile strength of chitin tablets produced at $300 \mathrm{MPa}-3 \mathrm{~s}$ dwell time and at $400 \mathrm{MPa}-1-3 \mathrm{~s}$ dwell time was too high to be measured by the tensile tester (>15 MPa).

\section{III.5.b Tablet disintegration}

Figure 11 shows the tablets disintegration time as a function of the dwell time at $200 \mathrm{MPa}$ compaction pressure. CC tablets have the shortest disintegration time (2-7 s) at all dwell time followed by Ludiflash ${ }^{\circledR}$, dry mix and finally chitin tablets. Prosolv ${ }^{\circledR}$ tablets did not disintegrate. An increase in the dwell time leads to an increase in the disintegration time for chitin tablets, other tablets were less affected by this change. Once again this points to the true plastic deformation and the plastic flow that the chitin particles go through with increased dwell time. 


\section{III.6 Formulation}

For the formulation studies with ibuprofen and paracetamol, 150-200 MPa compaction pressures were chosen as it is a typical compaction range for commercial tablet production and that CC tablets showed acceptable strength at this compaction pressure. The formulated tablets were analyzed for tabletability, disintegration time, dissolution profile and powder deformation. The formulations were prepared at different proportions with decreasing excipient concentration. The used CC-API proportions are 50-50, 40-60, 30-70, 25-75 and 20-80\% respectively.

\section{III.6.a Tensile strength}

Figure 12 shows the tabletability profiles of the 2 formulations at 150-200 MPa compaction pressure. Tablets compressed at $200 \mathrm{MPa}$ have higher tensile strength than that compressed at $150 \mathrm{MPa}$. For both formulations, tensile strength was proportional to the $\mathrm{CC}$ concentration which demonstrates its contribution to the strength of the formulation.

\section{III.6.b Tablet disintegration}

Figure 13 shows the disintegration time of the 2 formulations tablets compressed at 200 MPa. Both pure ibuprofen and paracetamol tablets did not disintegrate in water. With respect to ibuprofen formulation, the decrease in disintegration time of the tablets was proportional to the CC content. As for paracetamol formulations, rapid disintegration (5-6s) was obtained with all CC percentages. This may be explained by the insolubility of ibuprofen in water and that paracetamol is soluble.

\section{III.6.c Tablet dissolution}

Tablet dissolution was studied in phosphate buffer of pH 6.8 and 5.8 for ibuprofen and paracetamol formulations respectively. For both formulations and as observed in figure 14, we can notice faster API dissolution with higher $\mathrm{CC}$ content. In addition, the dissolution was retarded when the percentage of $\mathrm{CC}$ was lower than $30 \%$, indicating that the minimum effective level of CC to promote rapid dissolution is $30 \%$.

\section{III.6.d Powder deformation}

Figure 15a shows $\mathrm{P}_{\mathrm{y}}$ determined at $200 \mathrm{MPa}$ compaction pressure for the 2 formulations. $\mathrm{CC}$ has the highest $\mathrm{P}_{\mathrm{y}}$ revealing more fragmentary behavior of the powder when compared to the 
formulations. For both formulations, the increase in compaction pressure did not lead to significant change in $\mathrm{P}_{\mathrm{y}}$ (maximum difference of $25 \mathrm{MPa}$ ) as powder deformation occurs at intermediate pressures where no change in Heckel plots was observed for both formulations (figure $15 \mathrm{~b}$ - case of paracetamol). $\mathrm{P}_{\mathrm{y}}$ is directly proportional to $\mathrm{CC}$ concentration included in the formulations. $\mathrm{CC}$ contributes to the fragmentation behavior which in turn creates more bonding sites during compression due to particles fragmentation and higher tensile strength for tablets as observed in figure 12. Equally, these sites can create a percolating network of $\mathrm{CC}$ particles in the tablet causing a faster disintegration and better dissolution profile as observed in figures 13 and 14 [28].

\section{Conclusion}

Coprocessed Chitin- $\mathrm{CaCO}_{3}$ was studied as a multifunctional excipient for its compaction properties using different formulations and manufacturing conditions. It was found that Chitin$\mathrm{CaCO}_{3}$ has good tabletability, compressibility and compactibility profiles and did not show any tablet defects (capping, sticking) in the studied conditions. Chitin- $\mathrm{CaCO}_{3}$ did not require the addition of lubricant in the formulation and can be used at high compression speeds and with different dwell times. Chitin- $\mathrm{CaCO}_{3}$ enhances tablets tensile strength and promotes fast disintegration and dissolution when used in tablet formulations. This study shows additional tableting properties of coprocessed Chitin- $\mathrm{CaCO}_{3}$ and further confirms the findings of the previous work that it can be used as a novel and robust multifunctional excipient for fast disintegrating tablets produced by direct compression.

\section{Funding sources}

This work was supported by the CNRS-L/LU funding program (Lebanese National Council for Scientific Research CNRS-L and the Lebanese University LU) through the funding of the PhD of Mohammad CHAHEEN.

\section{Conflicts of interest}

None. 


\section{Figures legends}

Figure 1: Scanning electron microscopy of coprocessed chitin-calcium carbonate at different magnifications.

Figure 2: Transmission electron microscopy for chitin and chitin-calcium carbonate coprocessed powder.

Figure 3: (a) Tabletability, (b) compressibility and (c) compactibility profile of chitin-calcium carbonate, chitin, Ludiflash ${ }^{\circledR}$ and dry mix chitin-calcium carbonate.

Figure 4: Tablets tensile strength with different MgSt\% percentages at $200 \mathrm{MPa}$.

Figure 5: Ejection force of compressed tablets without MgSt at $200 \mathrm{MPa}$.

Figure 6: (a) $\mathrm{P}_{\mathrm{y}}$ and (b) Heckel plot of chitin-calcium carbonate with different $\mathrm{MgSt} \%$ at 200 MPa compaction pressure.

Figure 7: Disintegration time of tablets produced with different magnesium stearate percentages at $200 \mathrm{MPa}$.

Figure 8: Tablets tensile strength with different compression speeds at $200 \mathrm{MPa}$.

Figure 9: $\mathrm{P}_{\mathrm{y}}$ variation with different compression speeds at $200 \mathrm{MPa}$ compaction pressure.

Figure 10: Tablets tensile strength as a function of dwell time at $200 \mathrm{MPa}$.

Figure 11: Disintegration time of tablets compressed with different dwell times at $200 \mathrm{MPa}$.

Figure 12: Tensile strength of (a) chitin-calcium carbonate-ibuprofen and (b) chitin-calcium carbonate - paracetamol tablets.

Figure 13: Disintegration time of chitin-calcium carbonate-ibuprofen and chitin-calcium carbonate- paracetamol tablets compressed at 200MPa.

Figure 14: Dissolution profile of chitin-calcium carbonate-ibuprofen and chitin-calcium carbonate- paracetamol tablets at different concentrations compressed at 200MPa. 
Figure 15: (a) $\mathrm{P}_{\mathrm{y}}$ variation of CC- ibuprofen and CC-paracetamol formulations at $200 \mathrm{MPa}$. (b) Heckel plots of CC-paracetamol formulations at $200 \mathrm{MPa}$. 

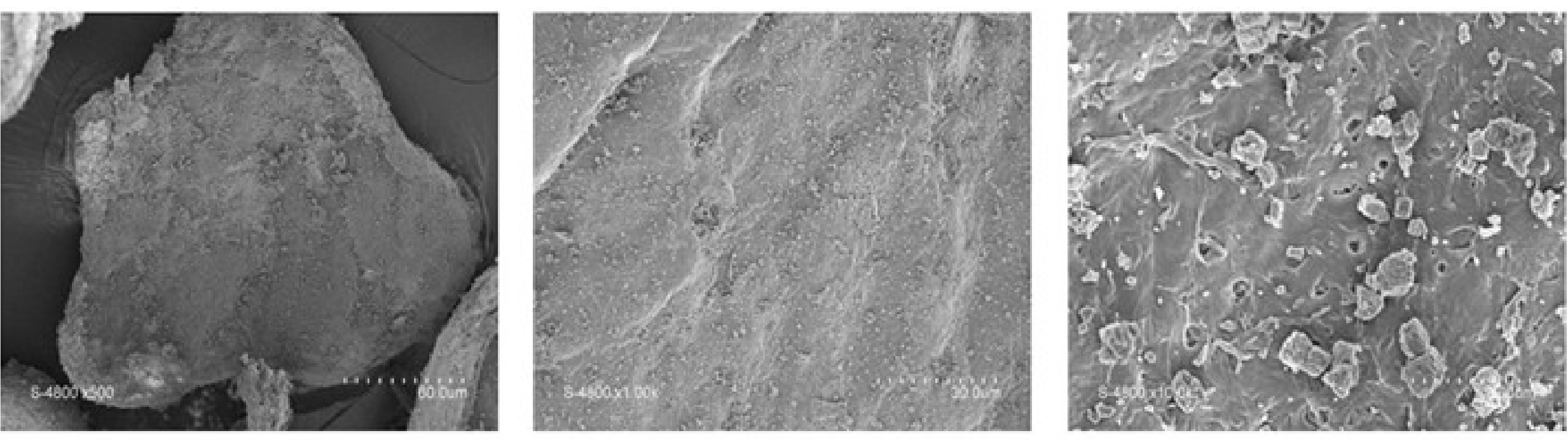

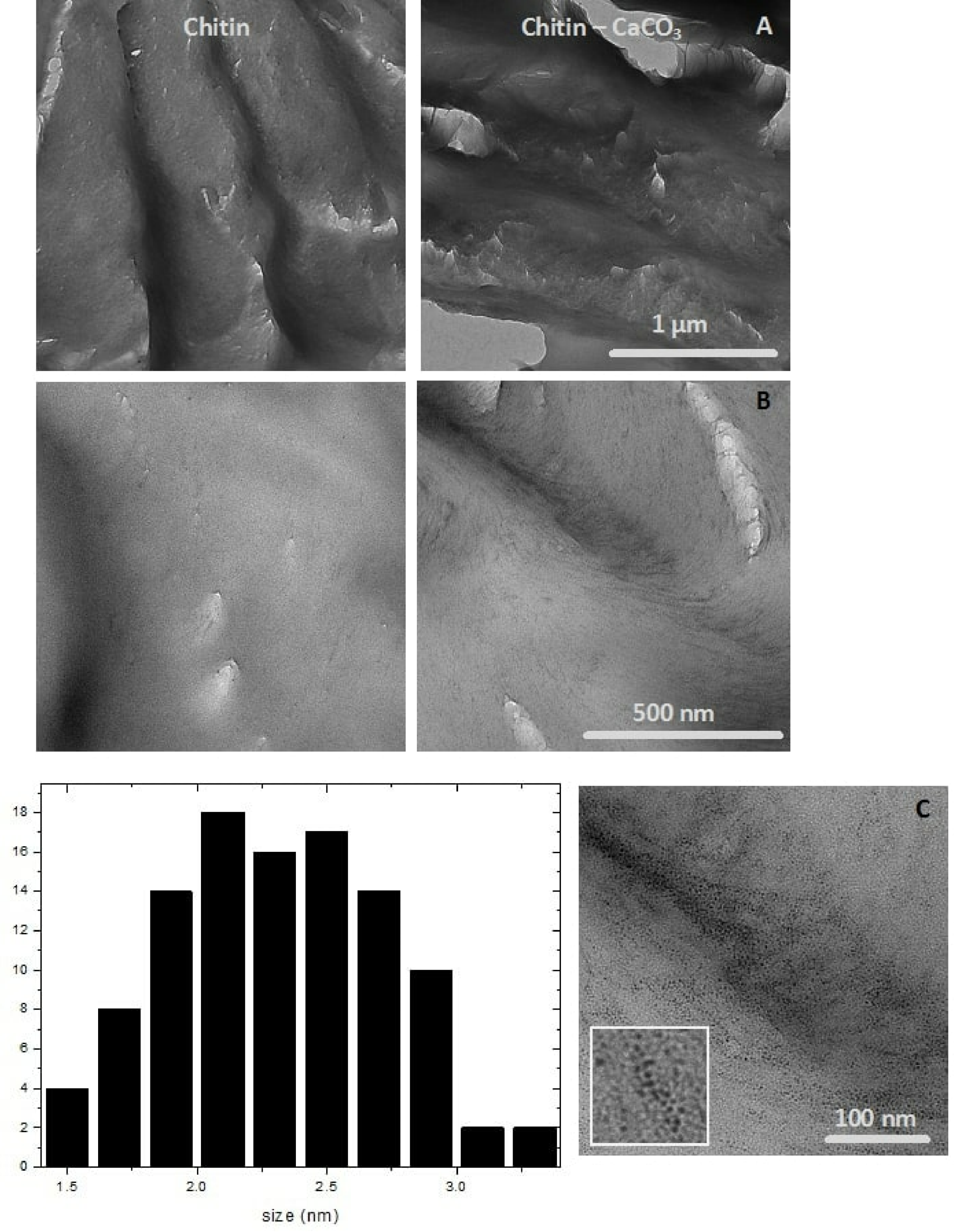

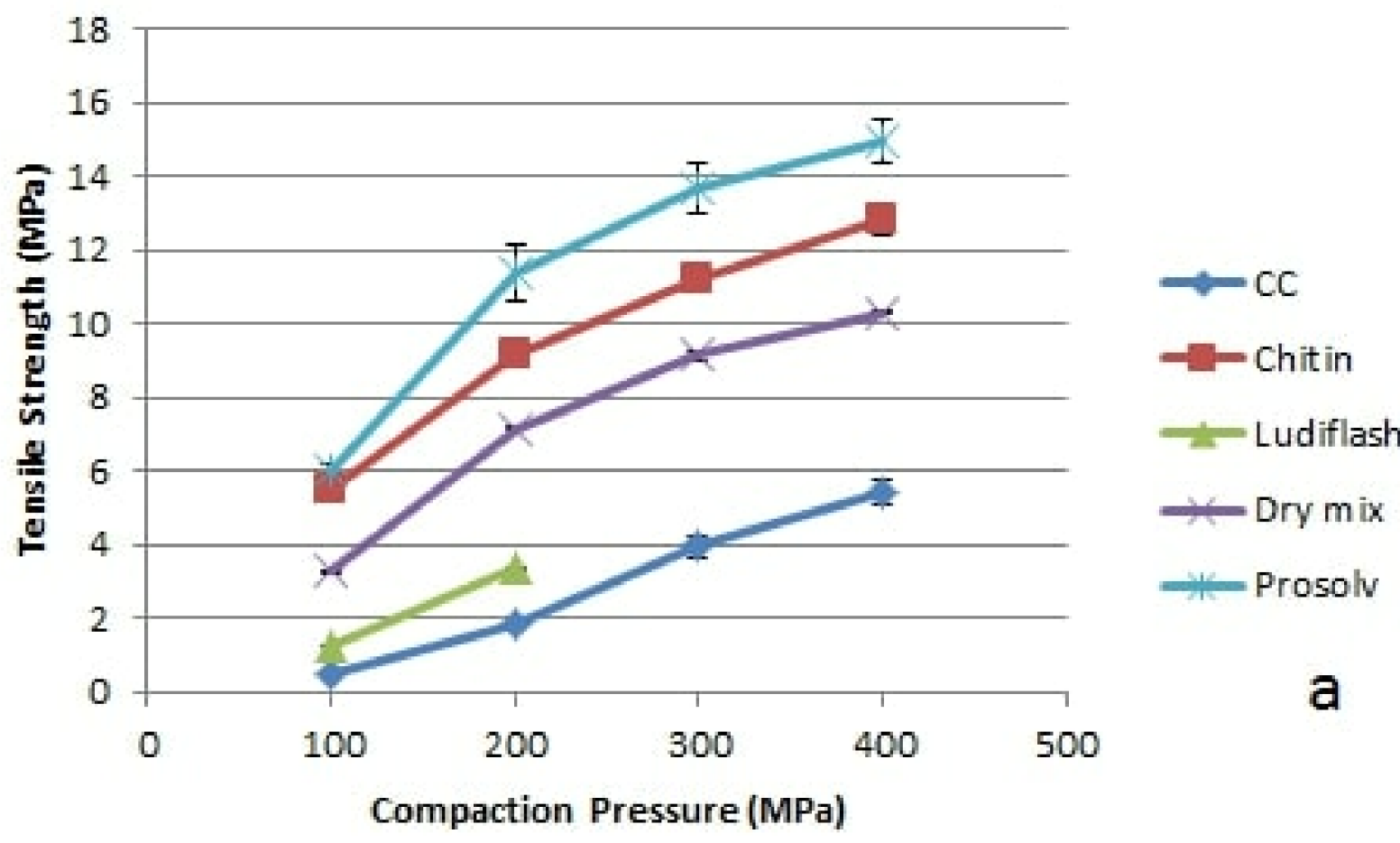

8
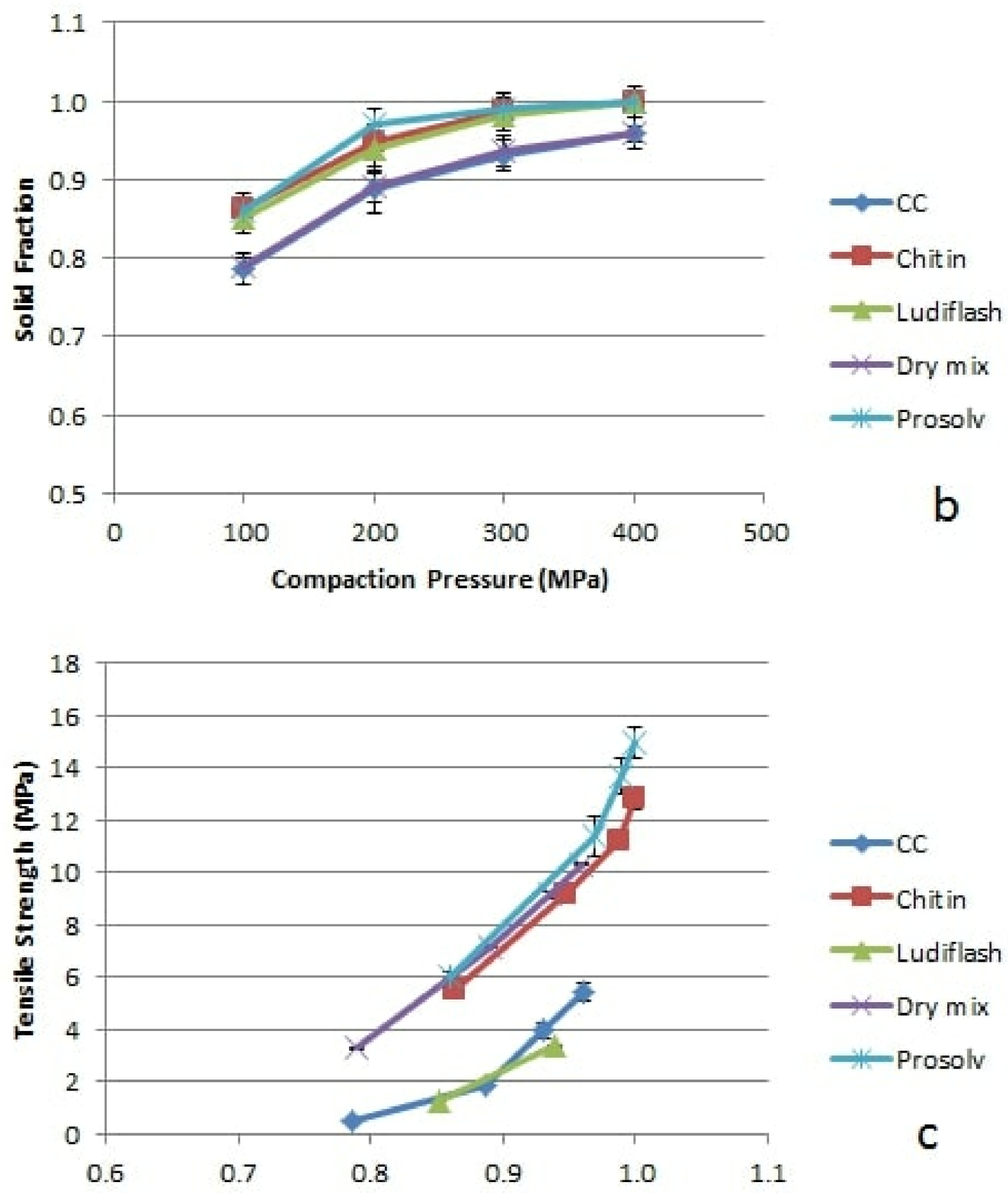

-Ludiflash

CDrymix

T-Prosolv

C

Solid Fraction 


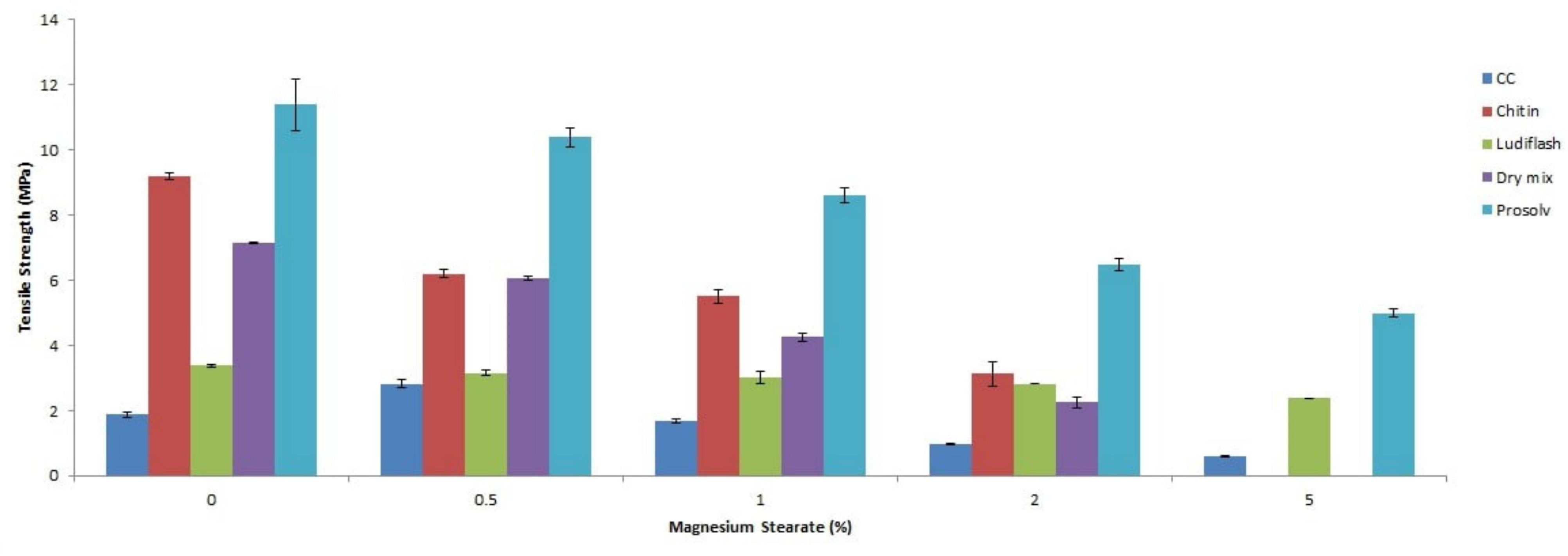




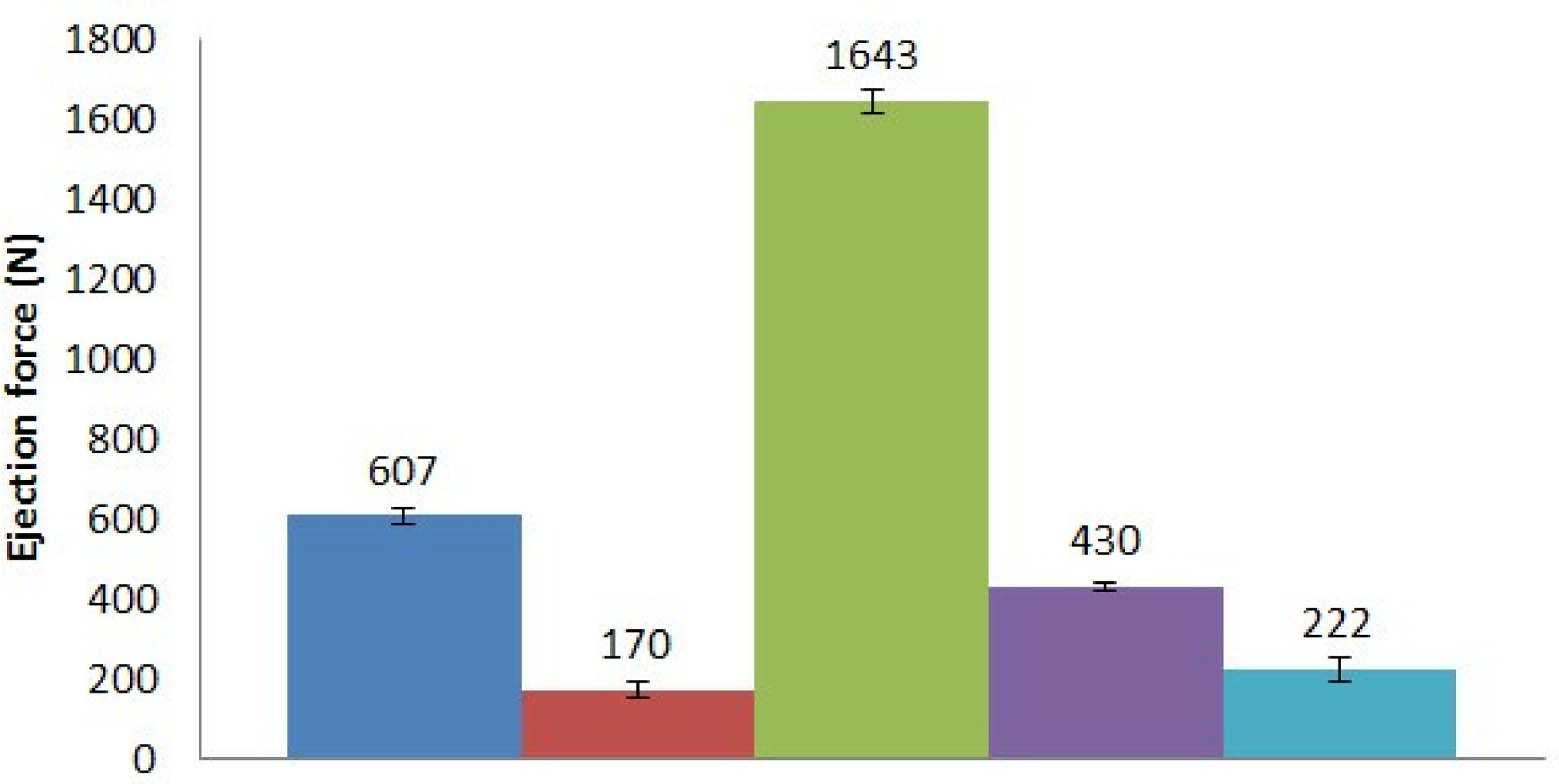




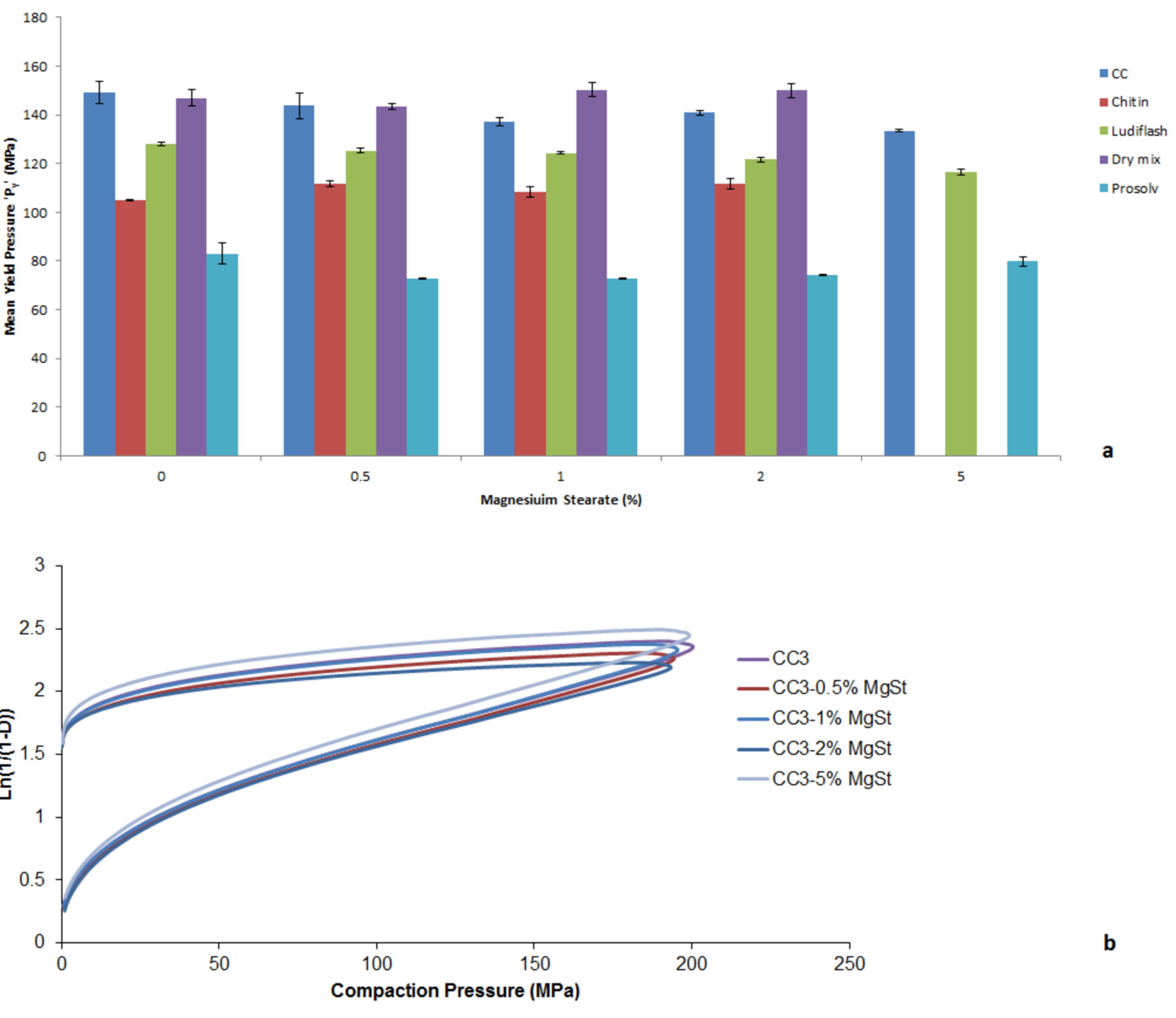




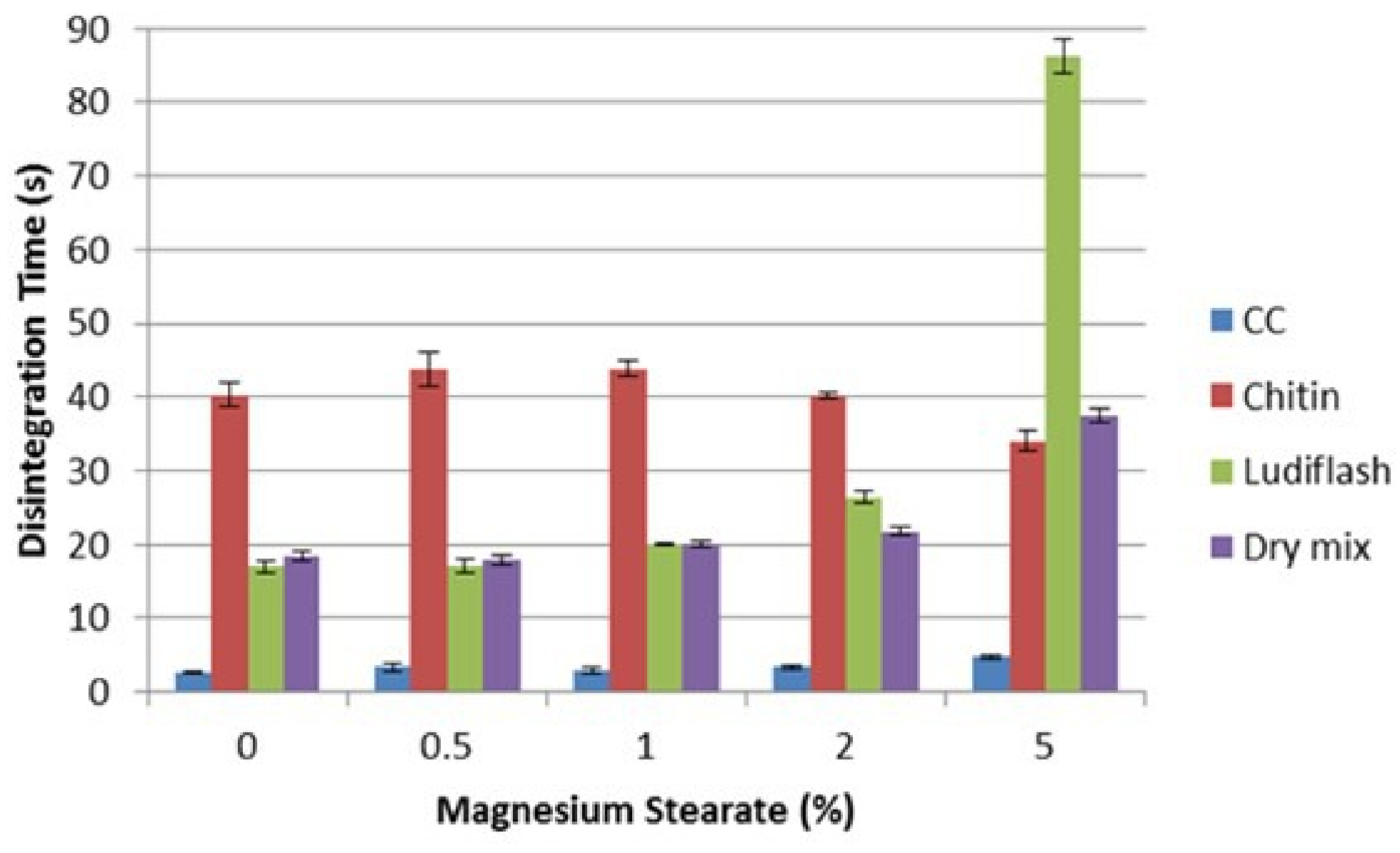




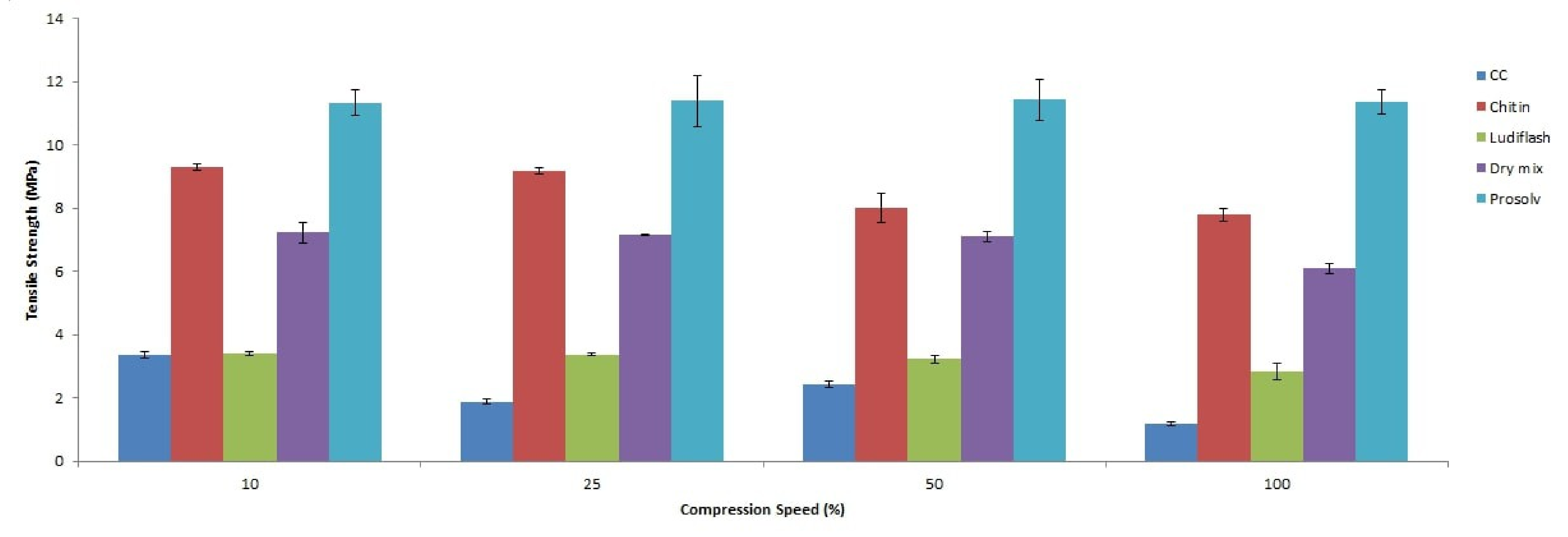




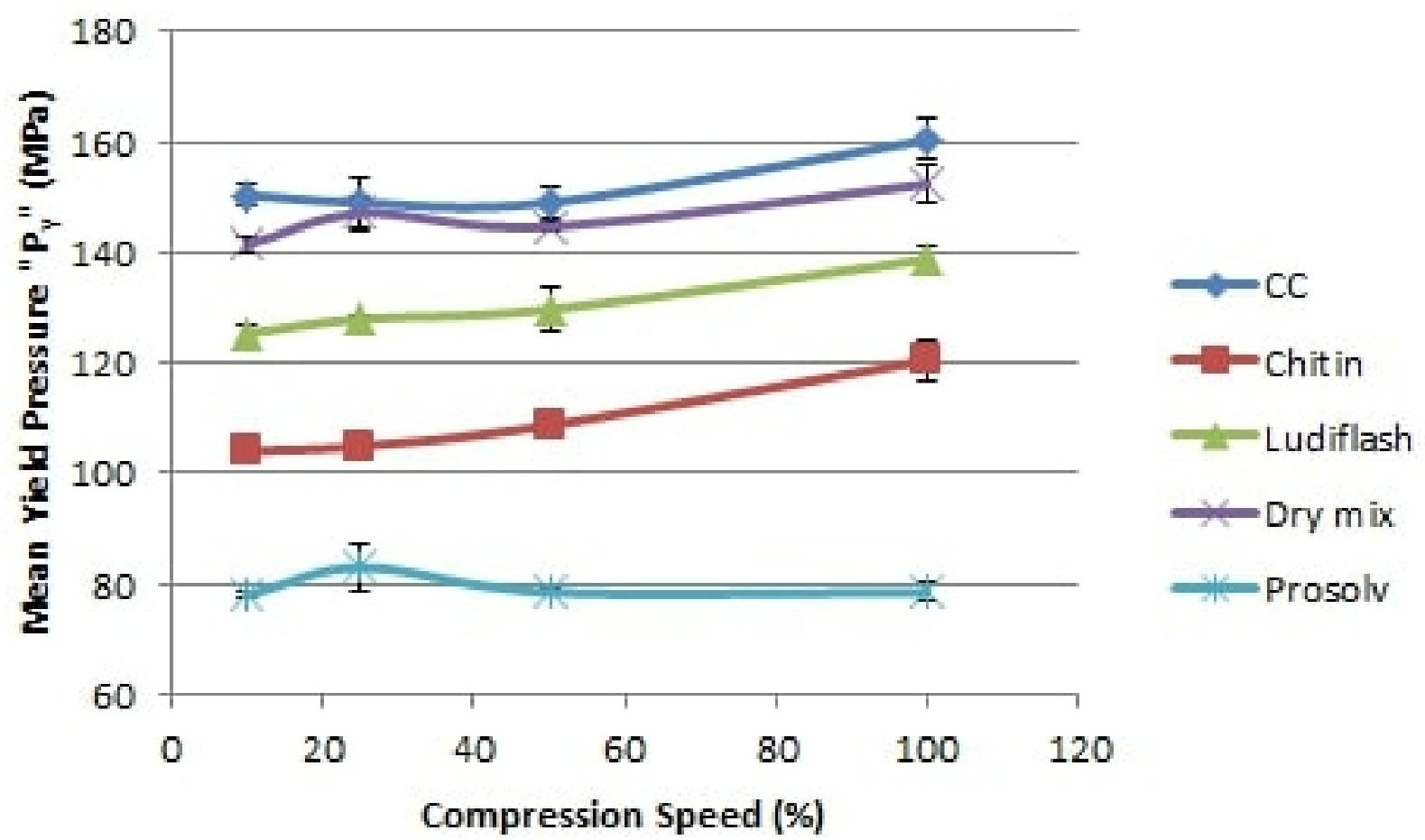




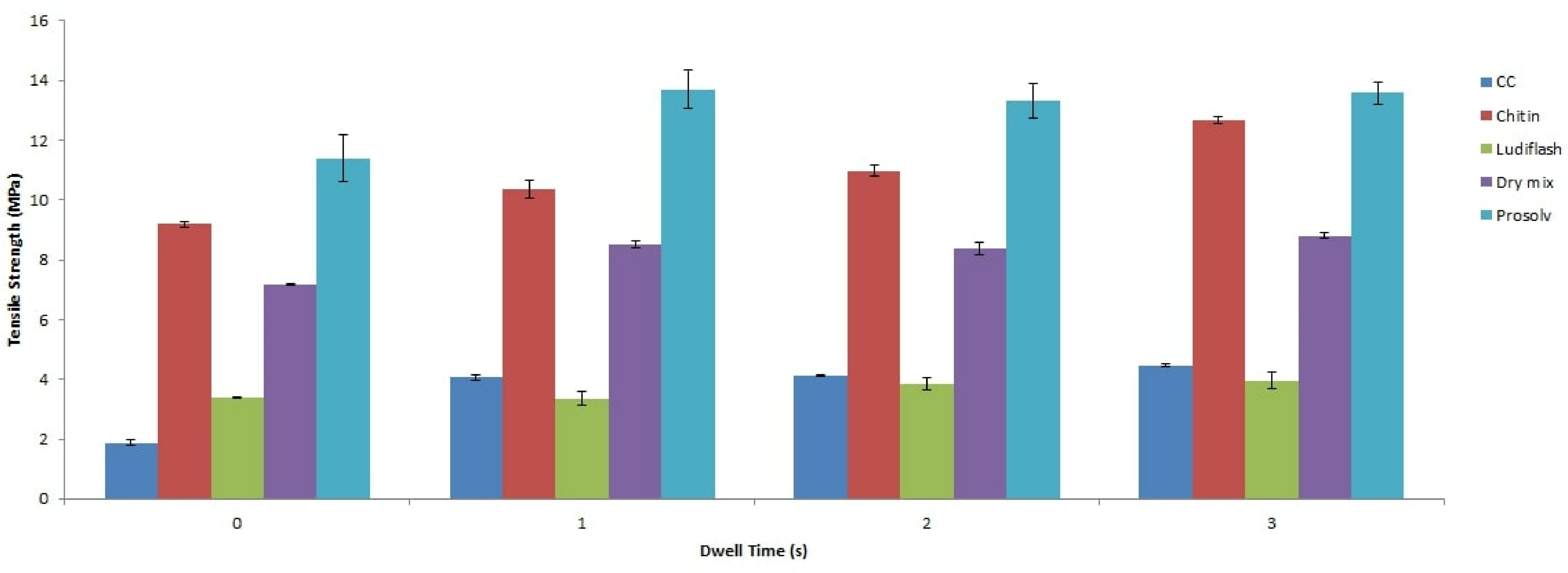




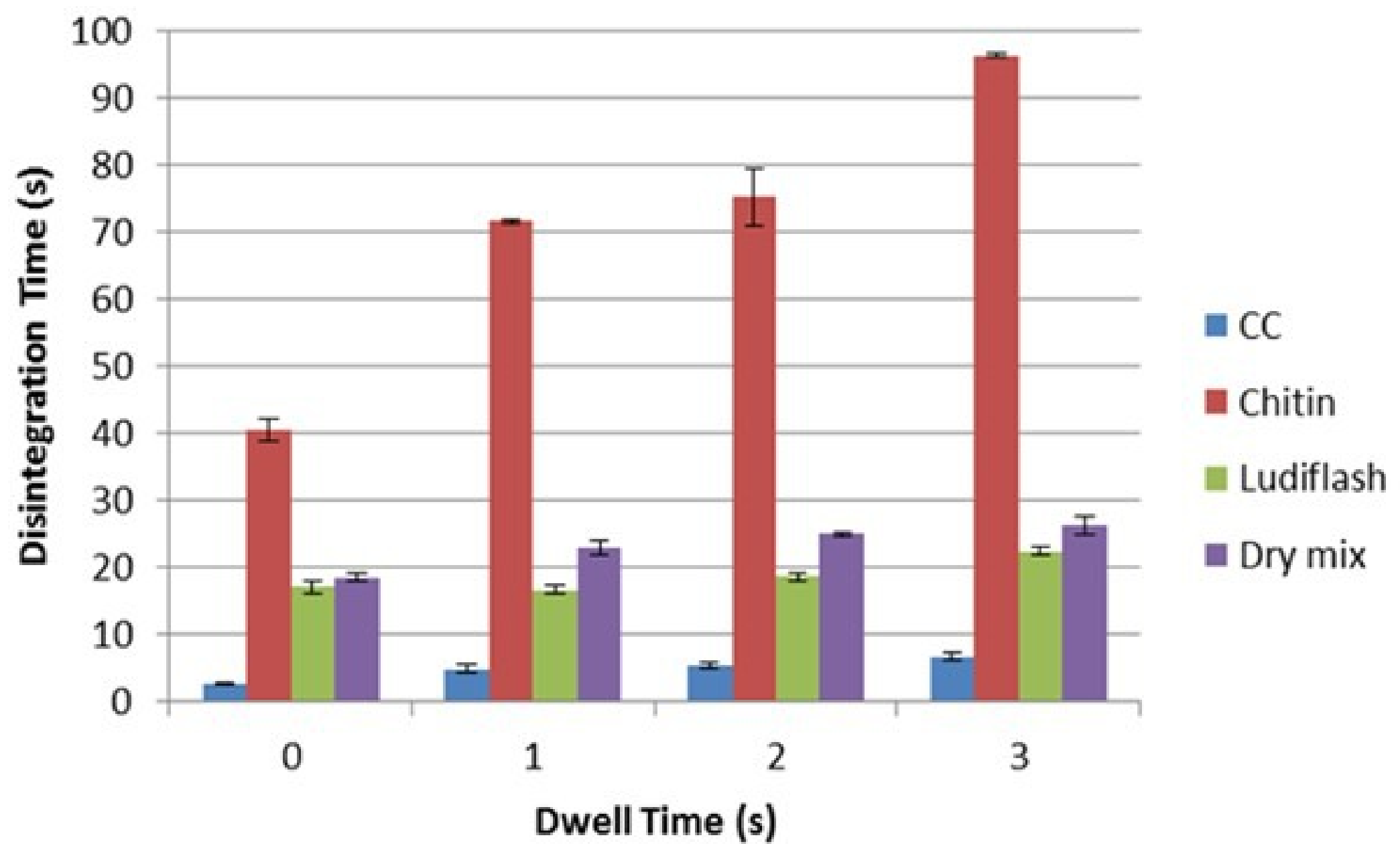




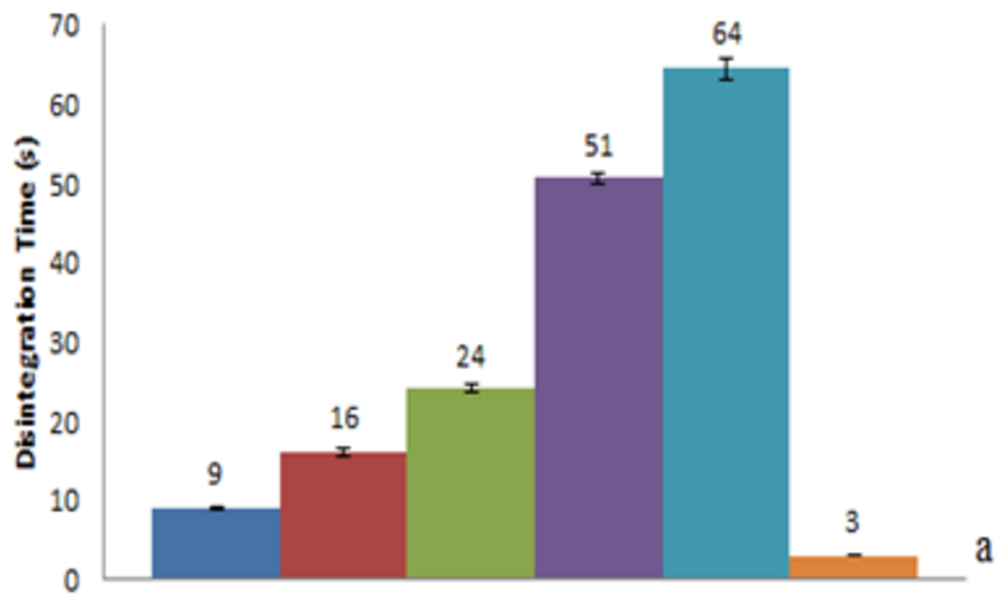

$=50-50=40-60=30-70=25-75=20-20=C C$

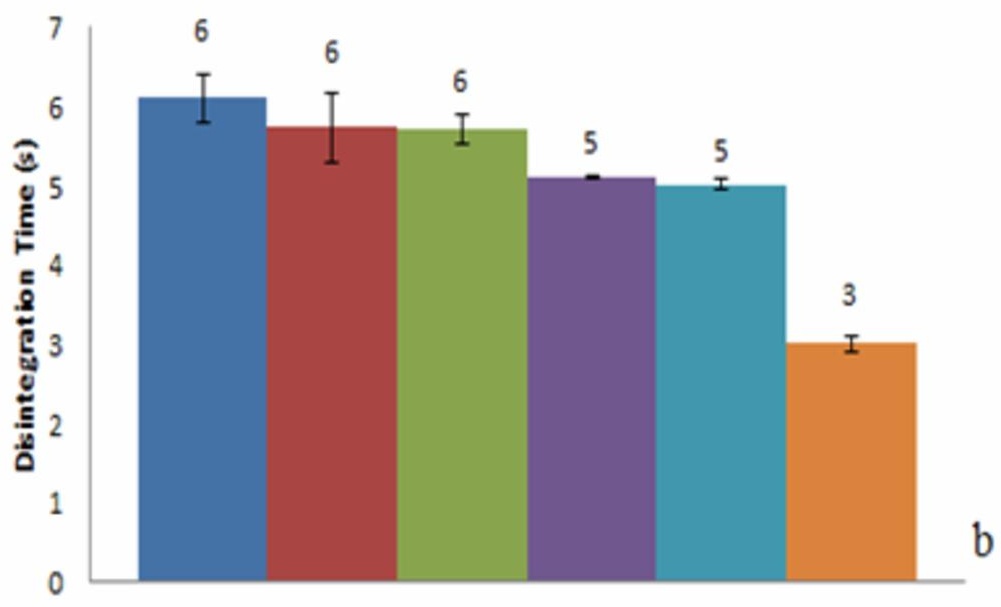



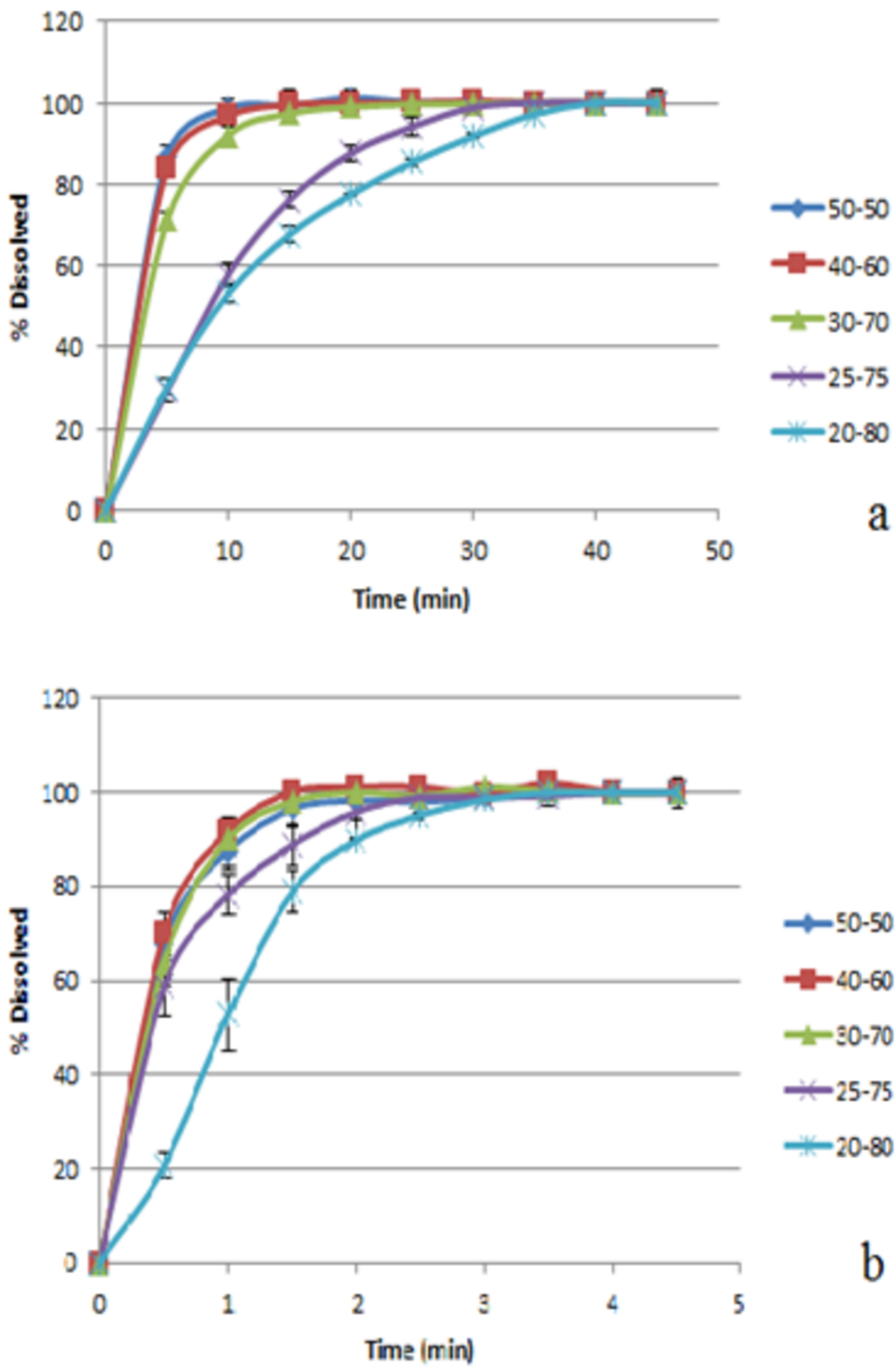

$-20-80$

b

Time (min) 


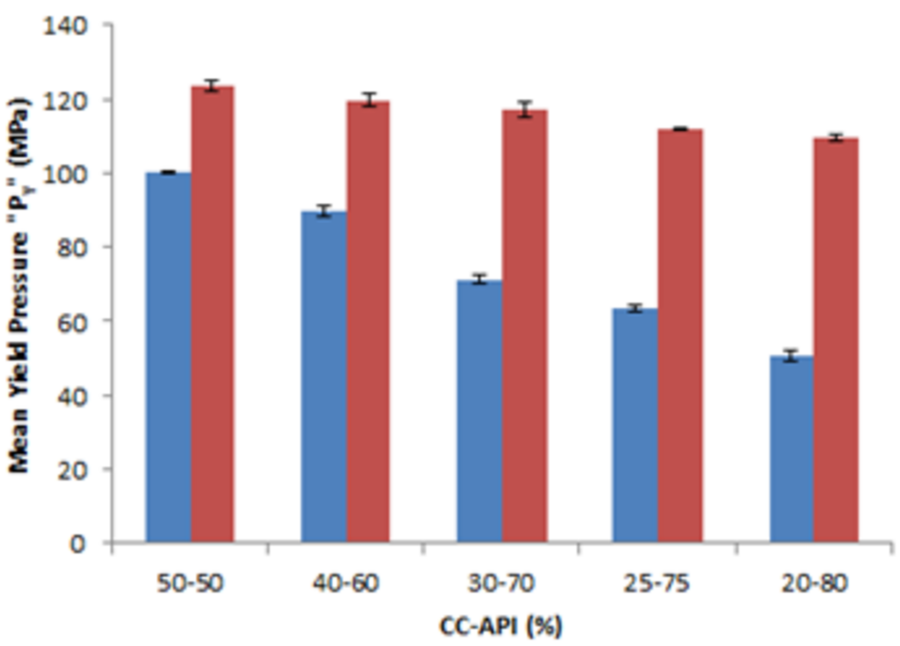

ECC-1Buprofen n CC-Paracetamol

a

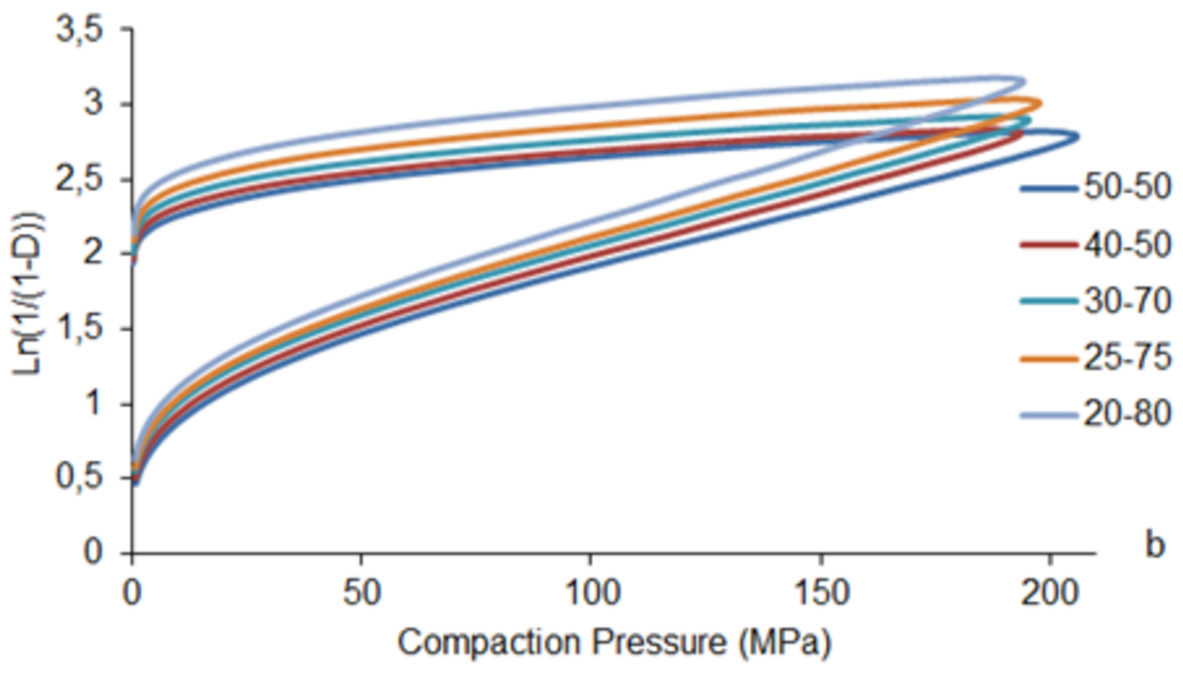




\section{References}

1. Jones DS. Pharmaceutics-dosage form and design. Pharmaceutical Press; 2008. 286 p.

2. Allen LV, Ansel HC. Ansel's pharmaceutical dosage forms and drug delivery systems. Tenth edition. Philadelphia: Wolters Kluwer Health; 2014. 794 p.

3. Augsburger LL, Hoag SW. Pharmaceutical dosage forms-tablets: rational design and formulation. Vol. 2. New York: Informa Healthcare USA; 2008. 576 p.

4. Gibson M. Pharmaceutical Preformulation and Formulation. CRC Press; 2016. 562 p.

5. Peppas NA, Khare AR. Preparation, structure and diffusional behavior of hydrogels in controlled release. Adv Drug Deliv Rev. 1993;11(1):1-35.

6. Bhor N, Bhusare S, Kare P. Multifunctional Excipients: The Smart Excipients. Int J Pure Appl Biosci. 2014;2(5):144-8.

7. Koo O, editor. Pharmaceutical excipients: properties, functionality, and applications in research and industry. Hoboken, New Jersey: John Wiley \& Sons, Inc; 2017. 348 p.

8. Rojas J. Excipient Design by Co-Processing for direct compression applications. In: Excipient applications in formulation design and drug delivery. Springer, Cham; 2015.

9. Chaudhari PD, Phatak AA, Desai U. A review: Coprocessed excipients-An alternative to novel chemical entities. Int J Pharm Chem Sci. 2012;1(4):1480-1498.

10. Patel H, Gohel M. A review on development of multifunctional co-processed excipient. J Crit Rev. 2016;3(2):48-54.

11. Chaheen M, Sanchez-Ballester N, Bataille B, Yassine A, Belamie E, Sharkawi T. Development of coprocessed chitin-calcium carbonate as multifunctional tablet excipient for direct compression. J. Pharm. Sci. 2018; 107(8): 2152-2159.

12. BASF. Ludiflash ${ }^{\circledR}$ [Internet]. BASF; 2012 [cited 2017 Dec 28]. Available from: https://pharmaceutical.basf.com/en/Drug-Formulation/Ludiflash.html 
13. JRS Pharma. Prosolv® SMCC [Internet]. JRS Pharma ; 2019 [cited 2019 Apr 18]. Available from: https://www.jrspharma.com/pharma_en/productsservices/excipients/hfe/prosolv-smcc.php

14. European Pharmacopeia. 8th ed. Strasbourg: European Directorate for the Quality of Medicines \&HealthCare, Council of Europe. Disintegration of Tablets and Capsules, 2016:229-301.

15. European Pharmacopeia. 8th ed. Strasbourg: European Directorate for the Quality of Medicines \&HealthCare, Council of Europe. Dissolution test for solid dosage forms, 2016:302-309.

16. European Pharmacopeia. 8th ed. Strasbourg: European Directorate for the Quality of Medicines \&HealthCare, Council of Europe. Buffer solutions, 2016: 5251-5257.

17. Tarlier N, Soulairol I, Bataille B, Baylac G, Ravel P, Nofrerias I, et al. Compaction behavior and deformation mechanism of directly compressible textured mannitol in a rotary tablet press simulator. Int J Pharm. 2015;495(1):410-9.

18. Shipar M. Effect of lubricant concentrtion on tablet properties (hardness and disintegration time). 2014. [internet] [cited 05 May 2018] . Toronto institute of pharmaceutical technology; Aavailable from: https://www.researchgate.net/publication/262677108_effect_of_lubricant_concentrtion_o n_tablet_properties_hardness_and_disintegration

19. Jarosz PJ, Parrott EL. Effect of Lubricants on Tensile Strengths of Tablets. Drug Dev Ind Pharm. 1984;10(2):259-73.

20. Augsburger LL, Hoag SW, editors. Pharmaceutical dosage forms. Tablets. 3rd ed. Vol. 3: Manufacture and process control. New York: Informa Healthcare USA; 2008. 311 p.

21. Badwan AA, Rashid I, Al Omari MMH, Darras FH. Chitin and Chitosan as Direct Compression Excipients in Pharmaceutical Applications. Mar Drugs. 2015;13(3):1519_ 47. 
22. Mohanty AK, Misra M, Drzal LT. Natural Fibers, Biopolymers, and Biocomposites. CRC Press; 2005. 896p

23. Cook GD, Summers MP. Effect of compression speed on the tensile strength of tablets of binary mixtures containing aspirin. J Pharm Pharmacol. 1990; 42(7): 462-467.

24. Roberts RJ, Rowe RC. The effect of punch velocity on the compaction of a variety of materials. J Pharm Pharmacol. 1985;37(6):377-384.

25. Augsburger LL, Hoag SW, editors. Pharmaceutical dosage forms. Tablets. 3rd ed. Vol. 1: Unit Operations and Mechanical Properties. New York: Informa Healthcare USA; 2008. $658 \mathrm{p}$.

26. Nokhodchi A, Ford JL, Rowe PH, Rubinstein MH. The effects of compression rate and force on the compaction properties of different viscosity grades of hydroxypropyl methyl cellulose 2208. Int J Pharm 1996; 129(1,2):21-31.

27. Akande OF, Ford JL, Rowe PH, Rubinstein MH. Pharmaceutics: The Effects of Lag-time and Dwell-time on the Compaction Properties of 1:1 Paracetamol/microcrystalline Cellulose Tablets Prepared by Pre-compression and Main Compression. J Pharm Pharmacol. 1998 Jan 1;50(1):19-28.

28. Leuenberger H, Leu R. Formation of a tablet: a site and bond percolation phenomenon. $\mathbf{J}$ Pharm Sci. 1992; 81(10): 976-982. 